REVIEW

\title{
Milroy disease and the VEGFR-3 mutation phenotype
}

\author{
G Brice, A H Child, A Evans, R Bell, S Mansour, K Burnand, M Sarfarazi, S Jeffery, P Mortimer
}

J Med Genet 2005;42:98-102. doi: 10.1136/jimg.2004.024802

Primary congenital lymphoedema (Milroy disease) is a rare autosomal dominant condition for which a major causative gene defect has recently been determined. Mutations in the vascular endothelial growth factor receptor 3 (VEGFR-3) gene have now been described in 13 families world-wide. This is a review of the condition based on the clinical findings in 71 subjects from 10 families. All 71 individuals have a mutation in VEGFR-3. Ninety per cent of the 71 individuals carrying a VEGFR-3 mutation showed signs of oedema, which was confined in all cases to the lower limbs. In all but two cases onset of swelling was from birth. Other symptoms and signs included cellulitis (20\%), large calibre leg veins $(23 \%)$, papillomatosis $(10 \%)$, and upslanting toenails (10\%). In males, hydrocoele was the next most common finding after oedema (37\%). Thorough clinical examination of these patients indicates that there are few clinical signs in addition to lower limb oedema. Rigorous phenotyping of patients produces a high yield of VEGFR-3 mutations.

See end of article for authors' affiliations

Correspondence to: Glen Brice, SW Thames Regional Genetics Unit, St George's Hospital Medical School, Cranmer Terrace, London SW17 ORE, UK; gbrice@sghms.ac.uk

Revised version received 15 September 2004 Accepted for publication 18 September 2004 n 1892 William Milroy described a family with congenital onset lymphoedema which was heritable, painless, non-progressive, and confined to the lower limbs. ${ }^{1}$ In his paper Milroy described a family consisting of 97 members, of whom 26, in six generations, had oedema. Some 35 years later Milroy attempted to follow up this family and was successful in locating 36 additional descendants. ${ }^{2}$

In William Osler's, The principles and practice of medicine, lymphoedema was first designated with Milroy's name. ${ }^{3}$ The lack of understanding of the cause of the condition is highlighted by the placing of the condition in the subsection of "Angioneurotic oedema" in the chapter entitled "Diseases of the nervous system". In his follow up paper of 1928, however, Milroy suggested that lymphatic blockage may be the underlying cause, but did not dismiss the idea of a vasomotor abnormality.

Primary lymphoedema is chronic tissue swelling, most commonly present in a lower limb, resulting from an intrinsic abnormality of lymph drainage. ${ }^{4}$ The term Milroy disease has unfortunately been increasingly used as a blanket term for all types of primary lymphoedema, whether or not the phenotype conforms to the original description by Milroy. Indeed Milroy himself did not clearly recognise that the type of lymphoedema he described was of a different aetiology to that described in 1898 by Henry Meige.5
Meige's family differed in that his cases had onset of oedema at puberty and a description of what appears to be acute cellulitis was given.

With the advent of molecular medicine the underlying cause of at least three types of dominantly inherited lymphoedema has been elucidated. Ferrell et $a l^{6}$ and Evans et $a l^{7}$ published evidence for a gene locus for congenital familial lymphoedema (Milroy disease) at chromosomal location 5q35. The gene mutated at this position was found to code for vascular endothelial growth factor receptor 3 (VEGFR-3), a member of the tyrosine kinase receptor family. ${ }^{89}$ This receptor, activated by VEGF-C and VEGF-D, is required for lymphatic development during embryogenesis. ${ }^{10}$ All mutations found to date have been located in either of the two intracellular kinase domains and are presumed to interfere with tyrosine kinase activation. $^{89}$

Mutations in the transcription factor gene, FOXC2, have been described in lymphoedemadistichiasis syndrome. ${ }^{11}{ }^{12}$ In this condition the onset of oedema is usually at or after puberty. In addition to oedema, individuals with this condition often have distichiasis (aberrant eyelashes growing from the meibomian glands). The extra lashes are frequently the presenting complaint in this condition as their development precedes the oedema. A recent study has found an increased incidence of ptosis, varicose veins, cleft palate, and congenital heart disease amongst mutation carriers. $^{13}$

More recently, mutations in the SOX18 gene have been reported to cause hypotrichosistelangiectasia-lymphoedema syndrome. ${ }^{14}$ The mutations in this gene are associated with a very distinct phenotype-hypotrichosis and lymphoedema presenting in childhood and telangiectasia or vascular naevi, particularly on the palms and soles. To date there have been no studies looking for mutations in SOX18 in patients with isolated primary lymphoedema.

However, most families with lymphoedema do not have changes within the genes discovered thus far, indicating that there are several more genes for lymphoedema to be discovered. Further evidence for genetic heterogeneity comes from studies of lymphoedema families in which the results are not consistent with linkage to either the VEGFR-3 or FOXC2 loci. ${ }^{15}$

Thirteen mutations have now been located in VEGFR-3 in families with primary congenital lymphoedema ${ }^{8916}$ although to date the detailed clinical phenotype of some of these families has been lacking. In this paper we describe the

Abbreviations: VEGFR-3, vascular endothelial growth factor receptor 3 
clinical phenotype of 71 patients from 10 families. All patients have mutations in one of the kinase domains of the VEGFR-3 gene. ${ }^{16}$

\section{METHODS}

\section{Patient ascertainment}

Twelve families were originally ascertained on the basis of a family history of congenital lymphoedema. Seven probands were ascertained following referral to local lymphoedema clinics. Of the remaining five, two were referred by interested physicians and three, including two from the USA, self referred. All other family members subsequently enrolled in the study were contacted via the proband in the first instance. Two of the 12 families were excluded from this study as no VEGFR-3 mutation was identified although their clinical features were consistent with a diagnosis of Milroy disease.

\section{Clinical phenotyping}

In total, 211 individuals from the 10 families were clinically examined by at least one of the authors (GB, AHC, PSM, $\mathrm{SM})$. Features of particular relevance included lymphoedema, venous abnormalities, and facial dysmorphism. Characteristic skin and nail changes, such as hyperkeratosis, skin thickening, increased skin markings, and fungal infections were also sought. Patients were questioned regarding their past medical history, family medical history, occurrence of cellulitis, venous problems, treatments, age at onset of swelling, and progression of the oedema over time. Care was taken to specifically exclude syndromes with a known genetic cause such as lymphoedema-distichiasis syndrome, hypotrichosis-lymphoedema-telangiectasia syndrome, and Turner and Noonan syndromes.

\section{Molecular diagnosis}

Initially, 12 affected probands with family histories of congenital lymphoedema were screened, looking for mutations in the VEGFR-3 gene. The results in all 12 families were consistent with linkage to chromosome 5q35. In 10 families, the entire gene was sequenced and eight mutations found. In the remaining two families, in which mutations were found, only the kinase domains were studied. Following discovery of a putative mutation in the proband, samples from all available affected and unaffected family members were analysed to ensure segregation of the sequence change with the affected phenotype.

\section{Lymphography/lymphoscintigraphy}

Ten patients (from five families) had previously undergone isotope lymphography (lymphoscintigraphy) or traditional $x$ ray lymphangiography. Results of gamma camera isotopic scans were based on the images obtained and comparing the uptake of radioactivity in regional lymph glands relative to the injected dose in the foot. ${ }^{17}$

\section{RESULTS}

The clinical findings are presented in table 1.

\section{Family demographics}

Following ascertainment via an affected proband, 211 individuals from 10 families, including unaffected spouses, were examined because of a family history of congenital lymphoedema. Of these, $64(31 \mathrm{M} / 33 \mathrm{~F})$ were found to be clinically affected with limb swelling or characteristic skin changes. All those thought to be clinically affected were found to carry VEGFR-3 mutations. Seven (10\%) clinically unaffected individuals $(4 \mathrm{M} / 3 \mathrm{~F})$, including three obligate gene carriers, were found to carry mutations in the absence of clinical signs. Following clinical review of these gene carriers, in light of their molecular analysis, initial impressions of their

\begin{tabular}{|c|c|c|}
\hline & Number & $M / F$ \\
\hline Total patients with VEGFR-3 mutations & 71 & $35 / 36$ \\
\hline Lymphoedema present & $64 / 71(90 \%)$ & $31 / 33$ \\
\hline \multicolumn{3}{|l|}{ Age of onset of oedema } \\
\hline Congenital & $62 / 64(97 \%)$ & $31 / 31$ \\
\hline Non-congenital & $2 / 64(3 \%)$ & $1 / 1$ \\
\hline \multicolumn{3}{|l|}{ Extent of oedema } \\
\hline Below knee & $60 / 64(94 \%)$ & $28 / 32$ \\
\hline Above knee & $4 / 64(6 \%)$ & $3 / 1$ \\
\hline Bilateral oedema & $55 / 64(85 \%)$ & $26 / 29$ \\
\hline \multicolumn{3}{|l|}{ Symmetry of oedema } \\
\hline Symmetrical swelling & $35 / 64(55 \%)$ & $14 / 21$ \\
\hline Right $>$ left & $15 / 64(23 \%)$ & $11 / 4$ \\
\hline Left>right & $5 / 64(8 \%)$ & $1 / 4$ \\
\hline \multicolumn{3}{|l|}{ Unilateral swelling } \\
\hline Right & $4 / 64(6 \%)$ & $2 / 2$ \\
\hline Left & $5 / 64(8 \%)$ & $3 / 2$ \\
\hline Hydrocoele & $13 / 35(37 \%)$ & \\
\hline Prominent veins & $16 / 71$ (23\%) & $9 / 7$ \\
\hline Cellulitis & $14 / 71$ (20\%) & $11 / 3$ \\
\hline "Ski jump" toenails & $10 / 71$ (14\%) & $5 / 5$ \\
\hline Papillomatosis & $7 / 71(10 \%)$ & $5 / 2$ \\
\hline Urethral abnormality & $3 / 71(4 \%)$ & $3 / 0$ \\
\hline
\end{tabular}

unaffected status have not changed. As only two out of 64 affected gene mutation carriers developed oedema later in life, it is unlikely, though still possible, that these seven individuals will develop oedema.

Clinically there was marked inter- and intrafamilial variation in the degree of oedema, ranging from only toes affected to bilateral swelling to the groin.

\section{Age of onset}

Of the 64 clinically affected individuals, 62 reported swelling from birth, with the two remaining individuals $(\mathrm{lM} / \mathrm{lF})$ reporting swelling first noted at ages 25 and 46, respectively. In two cases, where severe swelling of the dorsum of the foot was present at birth, oedema had reduced substantially by the age of 5. In all other cases the extent of swelling reportedly remained largely unchanged over time in contrast to lymphoedema-distichiasis, which tends to progress. Sclerosis of the skin with limited pitting seems to be a characteristic of Milroy disease and presumably limits swelling.

\section{Distribution of swelling}

Bilateral leg swelling was present in 55/64 (26M/29F) individuals. Of these, leg swelling was asymmetrical in 20 $(12 \mathrm{M} / 8 \mathrm{~F})$. An additional nine individuals were affected unilaterally $(5 \mathrm{M} / 4 \mathrm{~F})$. Expression ranged from no clinically evident swelling in seven individuals $(10 \%)$ to severe, bilateral swelling to the groin in two cases. Gender did not influence the degree of swelling.

\section{Urological abnormalities}

Of the 35 males with VEGFR-3 mutations, 13 (37\%) had developed a hydrocoele. In three of the 13 cases, bilateral hydrocoeles were reported, including a gene carrier with no lymphoedema when examined at the age of 42 . Three male patients underwent surgery in childhood for urethral abnormalities; two were described as urethral stricture and the third as mild hypospadias. A fourth individual had an operation on the penis at birth but details were unclear and this may have been for severe oedema causing phimosis.

\section{Veins}

True varicose veins were present in only three individuals, with only two females having undergone surgical procedures for the condition. Sixteen individuals were however noted to 


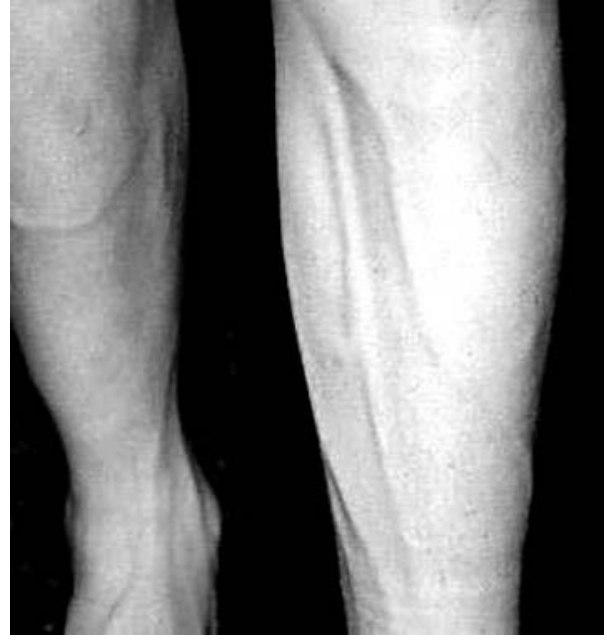

Figure 1 Tense prominent dilated veins noted in 16 patients (reproduced with permission).

have large calibre but non-tortuous long saphenous veins (fig l). These veins were not painful and not associated with any skin signs of venous disease.

\section{Other phenotypic abnormalities}

Upslanting of the nail on the big toe ("ski-jump" toenails), apparently present from birth, was noted in 10 patients (fig 2). In eight individuals the nails on the big toe were abnormally thickened and yellow in colour. Papillomatosis was noted on the toes of seven individuals. In all cases the papillomas were present over the base of the second toe (fig 3). All of these features can be secondary to lymphoedema of any cause.

There were no consistent dysmorphic features in the affected individuals.

\section{Infection}

Cellulitis was reported as a recurring problem in 14 cases $(11 \mathrm{M} / 3 \mathrm{~F})$ with males significantly more likely to be affected (Fisher's exact test, $\mathrm{p}=0.015$ ). Several patients were taking long term prophylactic antibiotics. Generalised problems with immunity were not evident from medical histories.

\section{Lymphangiography/lymphoscintigraphy}

Ten patients had undergone either lymphangiography or lymphoscintigraphy. In all four cases where lymphangiography was successful, lymphatic hypoplasia was noted. Two attempts at lymphangiography failed due to lack of

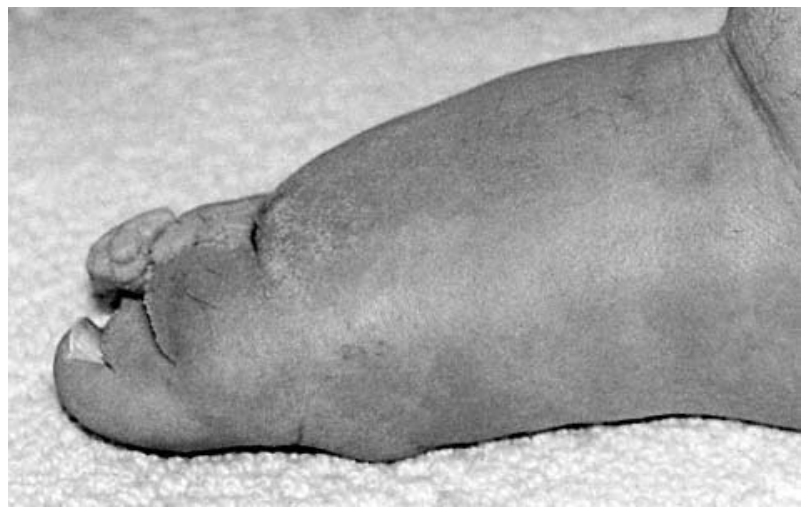

Figure 2 Upslanting ("ski-jump") toenails (reproduced with permission).

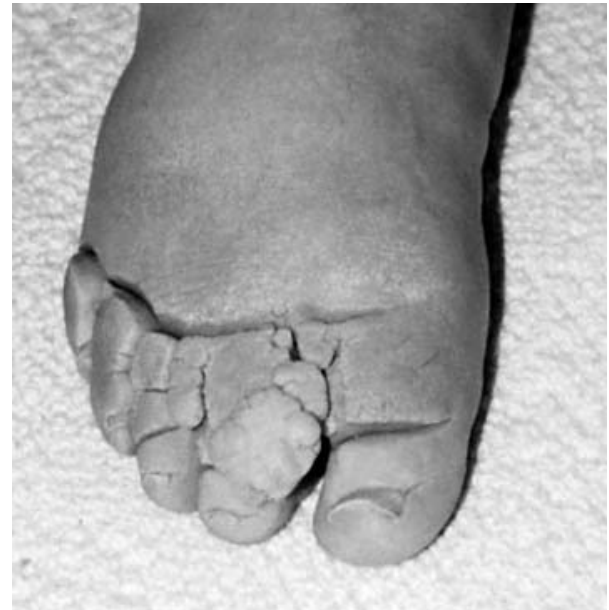

Figure 3 Papillomas over base of second toe (reproduced with permission)

lymphatics in the foot. The lymphoscintigram results in all six cases showed no, or little, uptake by peripheral lymphatics in the foot and consequently no, or little, uptake in the ilioinguinal nodes (fig 4).

\section{Treatment}

On presentation to the clinic only 16 patients were having active treatment for lymphoedema. Treatments were limited to massage and compression with hosiery or pneumatic therapy. Two female patients had undergone surgery; one had unilateral reduction surgery in childhood, while the other had removal of papillomas from the dorsum of the toes in her twenties.

\section{Molecular results}

All 71 patients had mutations within one of the two kinase domains of $V E G F R-3$. Details of all mutations have previously been published. ${ }^{16}$

\section{DISCUSSION}

Phenotypic abnormalities are described in 71 individuals with mutations in VEGFR-3 (Milroy disease). Seven were found to

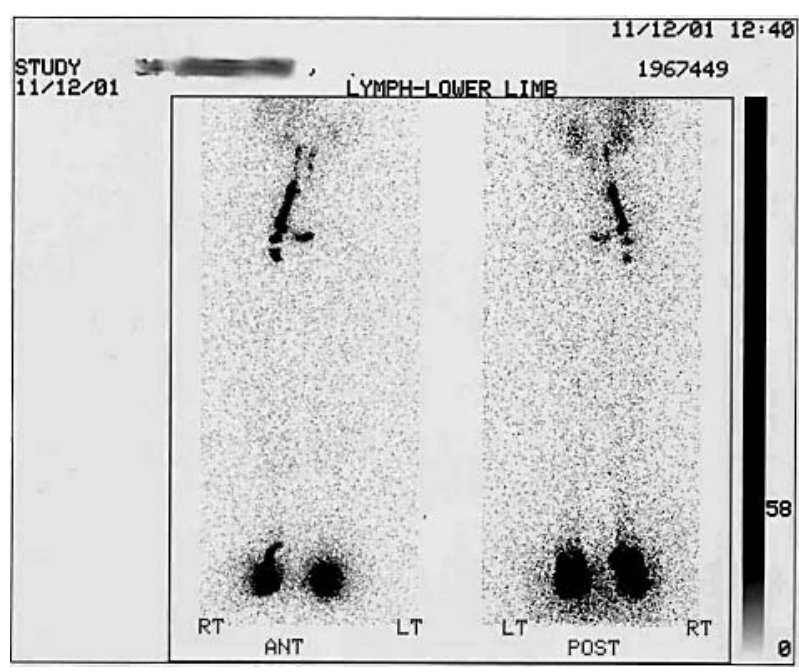

Figure 4 Lymphoscintigraphy: depot injections in right and left foot There is tracer uptake in the right ilio-inguinal nodes but no uptake on the left due to failure of peripheral lymphatic uptake. This patient had unilateral left leg swelling. 
carry disease causing mutations but were clinically unaffected. Of the 64 clinically affected individuals with VEGFR-3 mutations, below knee swelling, usually bilateral, was the most consistent finding. While onset at birth has been a requirement for the clinical diagnosis of Milroy disease, two individuals with mutations appeared to develop swelling much later in life, although it is possible subtle early changes may have been missed. Other investigators have also found that the majority of $V E G F R-3$ mutation carriers develop congenital swelling but rare cases appear later in life. ${ }^{18}$ In males, hydrocoele is the next commonest manifestation after swelling. Cellulitis is significantly more common in males, as was reported in association with lymphoedema-distichiasis syndrome. $^{13}$

Milroy disease has frequently been confused with other forms of congenital lymphoedema. This study excluded families without mutations in order to refine the phenotype of those with clinical Milroy disease and a VEGFR-3 mutation. Clearly, not all individuals with Milroy disease will have identifiable mutations in VEGFR-3. Milroy disease should be considered if the lymphoedema is congenital and confined to the lower limbs. The swelling is frequently "woody" in nature and associated with secondary changes which include deep creases over the toes, small dysplastic ("ski jump") toenails, and papillomas. The prominent wide calibre leg and foot veins are often a good clue to the underlying diagnosis as they are not seen with other causes of congenital lymphoedema.

Unlike other syndromes associated with lymphoedema, there are few associated abnormalities. Apart from hydrocoeles and some urethral abnormalities, there were no major structural abnormalities or consistent dysmorphic features.

$V E G F R-3$ is one of the most important genes responsible for lymphangiogenesis. Transgenic mice that are homozygous for VEGFR-3 mutations die before birth as a consequence of severe cardiovascular abnormalities. ${ }^{19}$ Chy mice $\left(\right.$ VEGFR $-3^{+/-}$) and mice in which the VEGFR-3 receptor is blocked, develop hind limb oedema similar to Milroy disease. ${ }^{20}$ In these mice fluorescence microlymphangiography failed to demonstrate functioning skin lymphatics (as was described in three human cases of Milroy disease ${ }^{21}$ ). Chy mice develop chylous ascites and some die soon after birth. In those that survive, chylous ascites resolves spontaneously never to reappear. No cases of chylous ascites have been described in those patients with VEGFR-3 mutations. To what extent transient ascites occurs in utero but then resolves is uncertain, but there have been no reports of this occurring.

Despite the germline mutation, lymphoedema appears to develop only in the lower limbs of humans or the hindlimbs of transgenic mice, but the reason for this is not clear. The onset of oedema at birth, before walking begins, suggests that orthostatic factors are not responsible for the limitation of oedema to the lower limbs. A failure to detect peripheral lymphatics with vital dyes prior to radiocontrast lymphography $^{22}$ or a failure of uptake of radiotracers by initial lymphatics during lymphoscintigraphy, as seen in six of our patients, would be in keeping with a failure in development of the most peripheral lymphatic vessels in the lower limbs.

Although there was a suggestion of hand swelling in one patient examined at the age of 1 year, our experience has shown that it is often difficult to differentiate between oedematous and normal skin in young children. ${ }^{7}$ Follow up of this patient has not been possible.

Because VEGFR-3 is involved in cardiovascular development before the receptor becomes restricted to the lymphatic endothelium, one could have expected some cardiovascular abnormalities, but none were observed. The finding of large calibre long saphenous veins needs further investigation.
Venous disease does not obviously develop in Milroy disease, unlike in lymphoedema-distichiasis syndrome. ${ }^{13}$

The finding of urethral stricture in two patients and hypospadias in a third is of interest. The majority of cases of urethral stricture in the general population are acquired, with the congenital form being extremely rare. Hypospadias occurs in less than $1 \%$ of male births. Our findings may be coincidental, but with an incidence of $8 \%$ in males in our series it is likely to be a true association, although there is no clear common embryological origin between the urethra and lymph system. ${ }^{23}$

The apparent non-penetrance of oedema in $10 \%$ of individuals with a VEGFR-3 mutation is important from a counselling point of view, both in terms of reproductive risk estimation and possible cosmetic effects of the condition.

For clinical purposes we propose that the term Milroy disease should be reserved only for those cases of primary lymphoedema which conform to the criteria proposed by Milroy: familial (autosomal dominant inheritance), congenital onset, non-progressive, lower limb involvement. However, theoretically, new dominant mutations may occur, or the parent may be non-penetrant. VEGFR-3 analysis in these situations would be helpful.

Theoretically, gene therapy would be an option for treatment particularly as successful reversal of the phenotype has been achieved in transgenic mice. ${ }^{24} 25$

\section{ACKNOWLEDGEMENTS}

This research was conducted within the network of the London IDEAS Genetic Knowledge Park. The research also utilised the services of the Biomics Unit of St George's Hospital Medical School.

\section{Authors' affiliations}

G Brice, R Bell, S Mansour, S Jeffery, SW Thames Regional Genetics Unit, St George's Hospital Medical School, London, UK

A H Child, A Evans, Department of Cardiological Sciences, St George's Hospital Medical School, London, UK

K Burnand, Department of Academic Surgery, St Thomas Hospital, London, UK

M Sarfarazi, Molecular Ophthalmic Genetics Laboratory, University of Connecticut Health Center, Farmington, CT, USA

P Mortimer, Department of Cardiac and Vascular Sciences (Dermatology), St George's Hospital Medical School, London, UK

$R B$ and $G B$ were supported by the British Heart Foundation. AHC was supported by the Bluff Field Charitable Trust. MS was supported by National Heart, Lung and Blood Institute, Grant \#: R01-HL66150.

Conflict of interest: none declared.

This study had the approval of the Wandsworth Local Research Ethics Committee and the University of Connecticut Health Center Institutional Review Board. Written consent was obtained from all participants or, in the case of a child, from their parent.

\section{REFERENCES}

1 Milroy WF. An undescribed variety of hereditary oedema. NY Med J Nov 5 , 1892.

2 Milroy WF. Chronic hereditary edema: Milroy's disease. JAMA 1928;91:1172-5

3 Osler W. The principles and practice of medicine, 4th ed. New York: D Appleton and Co, 1901

4 Mortimer PS. Managing lymphoedema. Clin Exp Dermatol 1995; 13:499-505.

5 Meige H. Dystrophie oedemateuse hereditarie. Press Med 1898;6:341-3.

6 Ferrell RE, Levinson KL, Esman JH, Kimak MA, Lawrence EC, Barmada MM Finegold DN. Hereditary lymphedema: evidence for linkage and genetic heterogeneity. Hum Mol Genet 1998;13:2073-8.

7 Evans AL, Brice G, Sotirova V, Mortimer P, Beninson J, Burnand K, Rosbotham J, Child A, Sarfarazi M. Mapping of primary congenital lymphedema to the 5q35.3 region. Am J Hum Genet 1999;64(2):547-55.

8 Karkkainen MJ, Ferrell RE, Lawrence EC, Kimak MA, Levinson KL, McTigue MA, Alitalo K, Finegold DN. Missense mutations interfere with VEGFR-3 signalling in primary lymphoedema. Nat Genet 2000;25(2):153-9.

9 Irrthum A, Karkkainen MJ, Devriendt K, Alitalo K, Vikkula M. Congenital hereditary lymphedema caused by a mutation that inactivates VEGFR3 tyrosine kinase. Am J Hum Genet 2000;67(2):295-301. 
10 Karkkainen MJ, Haiko P, Saino K, Partenen J, Taipale J, Petrova TV, Jeltsch M, Jackson DG, Talikka M, Rauvala H, Betsholtz C, Alitalo K. Vascular endothelial growth factor $C$ is required for sprouting of the first lymphatic vessels from embryonic veins. Nat Immunol 2004;5(1):74-80

11 Fang J, Dagenais SL, Erickson RP, Arlt MF, Glynn MW, Gorski JL, Seaver LH, Glover TW. Mutations in FOXC2 (MFH-1), a forkhead family transcription factor, are responsible for the hereditary lymphedema-distichiasis syndrome. Am J'Hum Genet 2000;67(6): 1382-8.

12 Bell R, Brice G, Child AH, Murday VA, Mansour S, Sandy CJ, Collin JR, Brady AF, Callen DF, Burnand K, Mortimer P, Jeffery S. Analysis of lymphoedema-distichiasis families for FOXC2 mutations reveals small insertions and deletions throughout the gene. Hum Genet 2001; 108(6):546-51

13 Brice G, Mansour S, Bell R, Collin JR, Child AH, Brady AF, Sarfarazi M, Burnand KG, Jeffery S, Mortimer P, Murday VA. Analysis of the phenotypic abnormalities in lymphoedema-distichiasis syndrome in 74 patients with FOXC2 mutations or linkage to 16q24. J Med Genet 2002;39(7):478-83

14 Irrthum A, Devriendt K, Chitayat D, Matthiijs G, Glade C, Steijllen PM, Fryns J-P, Van Steensel MAM, Vikkula M. Mutations in the transcription factor gene SOX1 8 underlie recessive and dominant forms of hypotrichosislymphedema-telangiectasia. Am J Hum Genet 2003;72:1470-8.

15 Holberg C, Erickson R, Bernas M, Witte M, Fultz K, Andrade M, Witte C. Segregation analyses and a genome wide linkage search confirm genetic heterogeneity and suggest oligogenic inheritance in some Milroy congenital primary lymphoedema families. Am J Med Genet 2001;98:303-12.

16 Evans AL, Bell R, Brice G, Comeglio P, Lipede, C, Jeffery S, Mortimer P, Sarfarazi $M$, Child AH. Identification of eight novel VEGFR-3 mutations in families with primary congenital lymphoedema. J Med Genet 2003:40(9):697-703.
17 Burnand KG Mortimer PS, Partsch $\mathrm{H}$. Diagnosis and investigation of lymphoedema. In: Browse NL, Burnand KG, Mortimer PS, eds. Diseases of the lymphatics. London: Arnold, 2003:110-50.

18 Levinson KL, Feingold E, Ferrell RE, Glover TW, Traboulsi El, Finegold DN. Age of onset in hereditary lymphedema. J Pediatr 2003;142:704-8.

19 Dumont DJ, Jussila L, Taipale J, Lymboussaki A, Mustonen T, Pajusola K, Breitman M, Alitalo K. Cardiovascular failure in mouse embryos deficient in VEGF receptor-3. Science 1998;282(5390):946-9.

20 Makinen T, Jussila L, Veikkola T, Karpanen T, Kettunen MI, Pulkkanen KJ Kauppinen R, Jackson DG, Kubo H, Nishikawa S, Yla-Herttuala S, Alitalo K. Inhibition of lymphangiogenesis with resulting lymphedema in transgenic mice expressing soluble VEGF receptor-3. Nat Med 2001;7(2):199-205.

21 Bollinger A, Isenring G, Franzeck UK, Brunner U. Aplasia of superficial lymphatic capillaries in hereditary and connatal lymphedema (Milroy's disease). Lymphology 1983;16:27-30.

22 Burnand KG, Mortimer PS, Partsch H. Diagnosis and investigation of lymphoedema. In: Browse NL, Burnand KG, Mortimer PS, eds. Diseases of the lymphatics. London: Arnold, 2003:123

23 Moore KL, Persaud TVN, eds. The developing human, 7th ed. Philadelphia Saunders, 2003.

24 Saaristo A, Veikkola T, Tammela T, Enholm B, Karkkainen MJ, Pajusola K, Bueler H, Yla-Herttuala S, Alitalo K. Lymphangiogenic gene therapy with minimal blood vascular side effects. J Exp Med 2002;196(6):719-30.

25 Yoon Y, Murayama T, Gravereaux E, Tkebuchava T, Silver M, Curry C, Wecker A, Kirchmair R, Hu CS, Kearney M, Ashare A, Jackson D, Kubo H, Isner J, Losordo DW. VEGF-C gene therapy augments post-natal lymphangiogenesis and ameliorates secondary lymphedema. J Clin Invest 2003;111:717-25.

Committee on Publication Ethics Seminar 2005

Friday 11 March 2005, 9.30 am - 5 pm, BMA House, London

This year's seminar will focus on COPE's new Code of Conduct for Editors and interactive workshops on common ethical and editorial dilemmas. The seminar is for editors, authors, and all those interested in increasing the standard of publication ethics.

The Code aims to set a new basic standard for the ethical conduct of editors and sets out guidelines for quality and correcting the record, standing by decisions made, ethics committee approval, consent for publication confidentiality of submitted material, guidance to authors, pursuing misconduct, relationship to publishers, owners, and advertisers, and conflict of interest. The code also creates a mechanism to refer a complaint to COPE if an editor has breached the code.

The seminar will include:

- The new Code of Conduct for Editors

- Dr lona Heath, Chair BMJ Ethics Committee-research, audit, and ethics committee approval

- COPE's new website-full text and keyword searching for COPE's advice on specific issues, for example research misconduct, conflict of interest, and deception

- Interactive workshops-common ethical and editorial dilemmas for editors

- Opportunities to network with other editors and share your experiences and challenges

The seminar is free for COPE members and $£ 30.00$ for non-members. Numbers are limited and early booking is advisable. For registrations or more information please contact Sam Knottenbelt at cope@bmigroup.com or call 0207383 6602. For more information on COPE see www.publicationethics.org.uk/ 